Terbit online pada laman web jurnal :
http://ejournal.amikompurwokerto.ac.id/index.php/telematikal
Telematika
Accreditated SINTA "2" Kemenristek/BRIN, No. 85/M/KPT/2020

\title{
Pemantau Suhu Menggunakan NodeMcu, IoT Dan Cayenne Pada Rack Server
}

\author{
Parma Hadi Rantelinggi ${ }^{1}$, Fridolin Febrianto Paiki ${ }^{2}$, Yosia Gadi ${ }^{3}$
}

${ }^{1,2,3}$ Program Studi Teknik Informatika

Universitas Papua

Email : p.rantelinggi@unipa.ac.id ${ }^{1}$,ff.paiki@unipa.ac.id ${ }^{2}$, yoisagadi07@gmail.com ${ }^{3}$

\begin{tabular}{l}
\hline A R T I C L E I N F O \\
\hline Article History: \\
Received June 23, 2020 \\
Revised July 7, 2020 \\
Received August 21, 2020 \\
Online August 31, 2020 \\
Keywords: \\
IoT \\
Temperature \\
Rack Server \\
DHT11 \\
NodeMcu
\end{tabular}

Kata Kunci:

IoT

Suhu

Rack Server

DHT11

NodeMcu

\section{Correspondence:}

Telephone: +6281342753880

E-mail:

p.rantelinggi@unipa.ac.id

\section{ABSTRACT}

The server is an essential part of the service provider that needs to be maintained. The server environment factor that needs to be monitored is the ideal temperature on the server rack. This study aims to implement temperature monitoring at the server rack. This research uses NodeMCU with DHT11 and IoT sensors to monitor and measure the temperature on the rack server. Temperature data on the rack server is monitored through Cayenne and displayed on smartphones and computers, so users can monitor the state of the rack server anywhere by accessing the internet. This study uses three rack servers connected with DHT11 sensors that can monitor temperature simultaneously. The results showed that the temperature increased accordingly due to the number of active servers in each rack, so it needed to be structured evenly on the server rack. Besides, the results of the study show that the application of NodeMCU with DHT11 and IoT sensors can monitor temperature well on the rack server, where the first rack server shows an average temperature of $19.3^{\circ} \mathrm{C}$, for the second rack $17.4^{\circ} \mathrm{C}$ and the third rack $21.8^{\circ} \mathrm{C}$.

\section{ABSTRAK}

Server menjadi bagian penting dalam penyedia layanan yang perlu dijaga peformanya. Faktor lingkungan server yang perlu pemantauan adalah suhu ideal pada rack server. Penelitian ini bertujuan menerapkan pemantau suhu pada rack server. Penelitian ini menggunakan NodeMCU dengan sensor DHT11 dan IoT untuk memantau dan mengukur suhu pada rack server. Data suhu pada rack server dipantau melalui Cayenne serta ditampilkan pada ponsel cerdas dan komputer, sehingga pengguna dapat memantau keadaan rack server di mana saja dengan mengakses internet. Penelitian ini menggunakan tiga rack server yang terhubung dengan sensor DHT11 yang dapat memantau suhu secara simultan. Hasil penelitian menunjukkan suhu meningkat karena faktor mesin yang aktif pada setiap rack, sehingga perlu penataan mesin secara merata pada rack server. Selain itu hasil penelitian menunjukkan penerapan NodeMCU dengan sensor DHT11 dan IoT dapat memantau suhu dengan baik pada rack server, dimana rack server pertama menunjukkan nilai rata-rata suhu $19,3^{\circ} \mathrm{C}$, untuk rack kedua $17,4^{\circ} \mathrm{C}$ dan rack ketiga $21,8^{\circ} \mathrm{C}$.

\section{PENDAHULUAN}

Perkembangan penelitian dalam topik jaringan nirkabel berkembang sangat pesat dalam satu dekade ini. Saat ini jaringan nirkabel menjadi bagian penting dan dibutuhkan pada perkantoran modern, karena teknologi jaringan nirkabel dapat digunakan untuk transmisi data dalam bentuk audio dan video secara otomatis pada lingkungan waktu nyata dan akses dari jaringan internet (Rantelinggi, Paiki, \& Rantelobo, 2017; Rantelinggi \& Djanali, 2015). Dalam sesi transmisi data diperlukan sebuah konsep komunikasi internet dengan beberapa perangkat. 
Suatu konsep dimana beberapa perangkat seperti processor, radio dan sensor yang memanfaatkan koneksi internet, untuk memantau kondisi kemudian menerima, mengolah data dan mengirimkan informasi ke pengguna disebut dengan Internet of Things (IoT) (Sethi \& Sarangi, 2017). Pengiriman informasi menggunakan sensor yang telah di pasangkan ke sebuah objek fisik seperti pada sistem pertanian cerdas dan rumah jamur (Mahmud et al 2018; Boonchieng, Chieochan, \& Saokaew, 2018) merupakan penerapan konsep IoT saat ini dengan memaksimalkan koneksi jaringan internet.

Konsep IoT dapat dimanfaatkan dalam monitoring server yang merupakan peralatan sentral, yang berfungsi untuk menyediakan pelayanan sehingga harus dijaga kehandalannya dalam mengontrol jaringan. Karena memiliki kinerja yang tinggi maka suhu mempunyai pengaruh pada server, maka ruangan server memiliki standar yang telah dikeluarkan oleh Telecommunications Industry Association (TIA) pada tahun 2012 yaitu suhu ruangan server memiliki standar temperatur $18-27$ derajat Celcius $\left({ }^{\circ} \mathrm{C}\right.$ ) (Gunawan \& Oktiawati, 2020). Kerusakan pada perangkat keras diakibatkan oleh suhu ruangan yang tinggi, sebaliknya gangguan listrik dapat disebabkan oleh suhu ruangan yang rendah.

Suhu ruangan server perlu dipantau secara periode, untuk itu maka diperlukan sistem yang berfungsi sebagai pemantau ruang server dengan memanfaatkan teknologi IoT (Kurniawan et al., 2019). Jika terjadi penyimpangan pada suhu yang di luar standar TIA maka dapat diketahui dan ada tindakan untuk menanganinya.

IoT mengacu kepada tiga jenis dari teknologi diantaranya persepsi, transmisi dan pemrosesan cerdas (Boonchieng, Chieochan, \& Saokaew, 2018). Protokol yang umumnya digunakan pada IoT adalah Message Queue Telemetry Transport (MQTT) yang merupakan dasar dari publishing/subscribing, protocol ini dirancang agar sederhana dan dapat diterapkan dengan mudah.

IoT pada umumnya dimanfaatkan untuk mencapai tujuan tertentu, dimana data diperoleh dari sensor yang saling berkomunikasi yang memanfaatkan jaringan komunikasi nirkabel. Data diolah menjadi informasi yang bermanfaat. Hal ini merupakan sebuah tantangan tersendiri dalam penelitian jaringan nirkabel.

Banyak Penelitian yang telah memanfaatkan IoT sebagai media untuk pemantauan secara langsung serta melakukan peringatan awal dalam mendeteksi kegagalan yang berbasis web dalam menyajikan data menjadi sebuah sistem pendukung keputusan (Prasetyo et al., 2020). Bahkan IoT digunakan untuk pemantauan kualitas air kolam, yang dikombinasikan dengan model komunikasi LoRa (Bhawiyuga \& Yahya, 2019), maupun menggunakan aplikasi berbasis mobile web (Rohadi et al., 2018; Sabiq \& Budisejati, 2017). Selain itu, IoT juga dimanfaatkan untuk pemantauan suhu dan kelembapan suatu ruangan, dimana bila terjadi perubahan maka sensor akan secara langsung mendeteksi dan menampilkan laporan pada ponsel cerdas (Hakiki, Darusalam, \& Nathasia, 2020).

Modul NodeMcu umumnya juga dikenal dengan ESP8266 adalah sebuah mikrokontroler yang menghubungkan jaringan Wi-Fi (Bajrami \& Murturi, 2018). Modul NodeMcu ini menghubungkan sensor ke jaringan Wi-Fi yang ada, serta berperan sebagai titik akses, sehingga modul ini dapat terhubung dengan perangkat lainnya (Ouldzira et al., 2019). DHT11 adalah sensor yang mempunyai fungsi mengukur suhu dan kelembapan di dalam ruangan (Mahmud et al., 2018). Sensor ini mampu menghasilkan sinyal digital dengan keluaran yang kehandalannya tinggi dan stabilitas jangka panjang (Rahman, Hashim, \& Ahmad, 2020).

Cayenne dirancang untuk membantu pengembang agar dapat menggunakan teknologi drag and drop, selain itu Cayenne menyediakan akses untuk fitur Arduino serta berbagai jenis platform IoT dengan 
cukup mudah dalam pengaturannya (Lestariningsih et al., 2019). Cayenne digunakan untuk menmvisualisasikan data yang diperoleh, selain itu Cayenne dapat memantau melalui ponsel cerdas yang terkoneksi dengan internet (Adhiwibowo, Daru, \& Hirzan, 2020).

Dalam penelitian ini di bangun suatu sistem pemantau suhu pada masing-masing rack server, yang dapat memberikan informasi apabila terjadi perubahan suhu pada rack server secara waktu nyata, hal ini merupakan kontribusi dalam penelitan ini dimana sistem dibangun menggunakan NodeMcu sebagai mikrokontroler, modul ESP8266 sebagai alat penghubung ke Wifi dimana Access Point (AP) yang terkoneksi ke internet agar dapat dipantau secara waktu nyata, untuk deteksi suhu maka digunakan DHT11 dengan mengakuisisi data suhu dengan interval waktu 15 detik. Data yang diperoleh diolah dengan platform Cayenne.

\section{METODE PENELITIAN}

Dalam tahapan ini yang dibahas adalah metode yang dipakai dalam penelitian ini yang dibahas menjadi beberapa bagian dalam rancangan model penelitian ini. Dalam penelitian ini menggunakan langkah-langkah dengan tahapan menggunakan System Development Life Cycle (SDLC) (Boonchieng, Chieochan, \& Saokaew, 2018), dimana penelitian dibagi dalam empat tahap. Pertama studi kebutuhan dan kelayakan, tahap kedua yaitu analisa dan desain, tahap ketiga adalah implementasi dan yang terakhir adalah tahap validasi sistem.

\section{Studi Kebutuhan dan Kelayakan}

Penelitian ini untuk merancang dan membangun purwarupa untuk pemantauan suhu rack server, karena rack server perlu dikontrol tingkat suhu nya untuk menjaga kinerja masing-masing mesin server. Suhu ideal dalam ruangan server adalah $18^{\circ} \mathrm{C}$ sampai dengan $27^{\circ} \mathrm{C}$, selain itu purwarupa yang di bangun harus sederhana dalam perawatannya. Suhu dikirim ke ponsel cerdas atau komputer yang kemudian dicatat pada perangkat seluler dan komputer.

\section{Analisa dan Desain}

Unit Pelayanan Terpadu (UPT) Teknologi Informasi dan Komunikasi (TIK) Universitas Papua (UNIPA) adalah lokasi selama penelitian, karena dianggap layak dimana UPT TIK UNIPA memiliki ruangan server dan memiliki tiga rack server. Dalam penelitian ini perancangan purwarupa untuk pemantauan suhu pada rack server yang merupakan fokus dari penelitian ini. Denah server dan sensor dapat dilihat pada Gambar 1. 


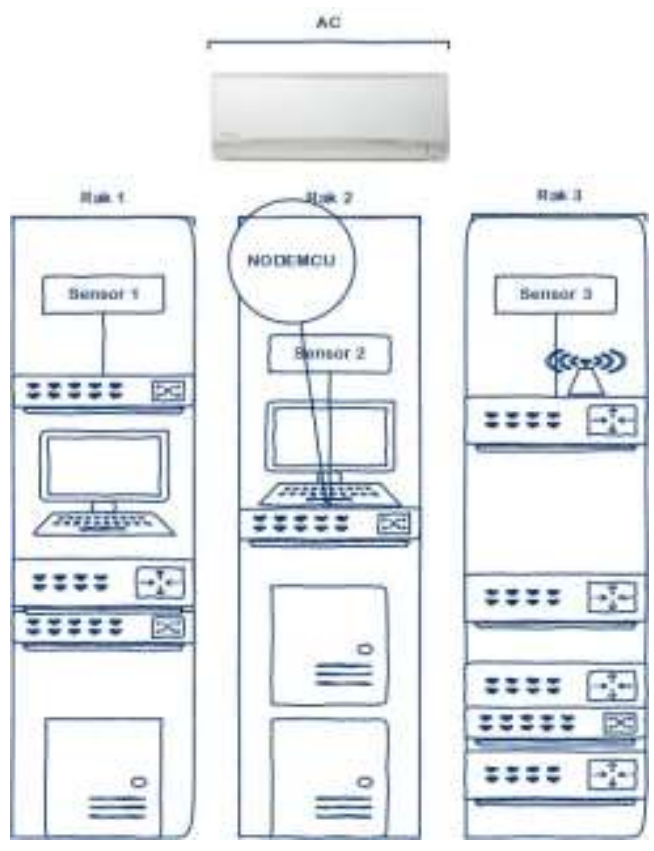

Gambar 1. Denah Server dan Sensor

Pada penelitian ini sensor dimanfaatkan untuk mengukur suhu secara waktu nyata. NodeMcu berfungsi sebagai perangkat keras yang di aplikasikan dengan Wi-Fi untuk IoT yang terhubung dengan layanan internet. Aplikasi yang digunakan untuk mengirim data suhu ke internet adalah Cayenne sekaligus berfungsi menampilkan data suhu secara waktu nyata pada ponsel cerdas dan komputer. Konsep perancangan pemantauan suhu rack server berbasis IoT dengan menggunakan NodeMcu dapat dilihat pada Gambar 2.

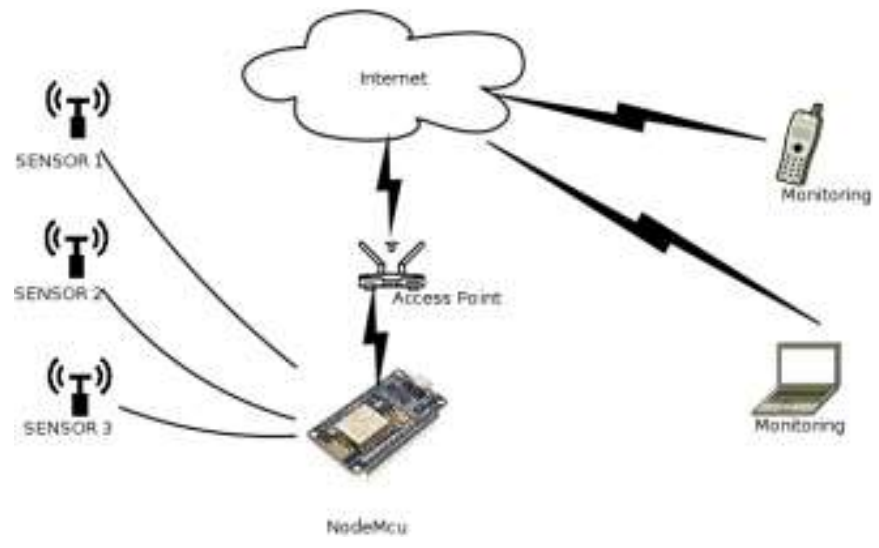

Gambar 2. Perancangan Pemantauan Suhu

Penelitian ini dibangun menggunakan beberapa perangkat keras yang dapat di lihat pada Tabel 1, yang menjelaskan nama perangkat dan fungsi nya masing - masing.

Tabel 1. Perangkat Keras dan Fungsi

\begin{tabular}{lll}
\hline No & Nama perangkat keras & \multicolumn{1}{c}{ Fungsi } \\
\hline 1 & NodeMcu lolin V.3 & $\begin{array}{l}\text { Mengolah, membangun data suhu } \\
\text { untuk selanjutnya di kirim ke } \\
\text { Cayenne. }\end{array}$ \\
\hline 2 & DHT11 & $\begin{array}{l}\text { Memantau objek suhu yang } \\
\text { memiliki tegangan analog sebagai } \\
\end{array}$ \\
& & $\begin{array}{l}\text { luaran yang selanjutnya diolah } \\
\text { dengan mikrokontroler }\end{array}$ \\
& & $\begin{array}{l}\text { Untuk menghubungkan NodeMcu } \\
\text { dengan sumber listrik. }\end{array}$ \\
\hline 3 & Kabel Jumper & Berfungsi menaikkan dan \\
& & menurunkan tegangan \\
\hline 4 & Regulator LM2596 & \\
\hline
\end{tabular}




\begin{tabular}{lll}
\hline 5 & Adaptor 5 Volt & $\begin{array}{l}\text { Berfungsi menyambungkan } \\
\text { sumber tegangan DC }\end{array}$ \\
\hline 6 & Acces Point & $\begin{array}{l}\text { Menguhubungkan NodeMcu } \\
\text { dengan Internet }\end{array}$ \\
\hline 7 & Telepon Pintar & $\begin{array}{l}\text { Berfungsi untuk monitoring suhu } \\
\text { menggunakan android }\end{array}$ \\
\hline
\end{tabular}

Untuk perangkat lunak dapat dilihat pada Tabel 2, dimana dijelaskan komponen perangkat lunak dan fungsi nya.

Tabel 2. Perangkat Lunak dan Fungsi

\begin{tabular}{lll}
\hline No & Nama perangkat lunak & \multicolumn{1}{c}{ Fungsi } \\
\hline 1 & Arduino IDE & $\begin{array}{l}\text { Text editor untuk membangun, } \\
\text { membuka, mengedit dan } \\
\text { memvalidasi kode yang akan di } \\
\text { upload ke NodeMcu }\end{array}$ \\
\hline 2 & Google Chrome & $\begin{array}{l}\text { Aplikasi web untuk mmebuka web } \\
\text { Cayenne }\end{array}$ \\
\hline 3 & Ms. Office Excel 2013 & $\begin{array}{l}\text { Berfungsi mengolah data yang } \\
\text { diperoleh dari DHT11 }\end{array}$ \\
\hline 4 & Ms. Office Visio 2013 & $\begin{array}{l}\text { Berfungsi untuk merancang } \\
\text { gambaran rangkain }\end{array}$ \\
\hline 5 & Aplikasi Cayenne & $\begin{array}{l}\text { Berfungsi memantau suhu di } \\
\text { telepon pintar yang berbasis } \\
\text { android. }\end{array}$ \\
\hline
\end{tabular}

Dalam penelitian ini, rangkaian perangkat keras terdapat tiga kabel yang dipakai yaitu kabel daya positif, kabel negatif dan kabel data. Arus listrik yang masuk dari adapter ke jack DC sebesar 12 Volt diturun dengan menggunakan regulator LM2596 menjadi 4,55 Volt, kabel positif dan negatif terhubung dengan NodeMcu pada pin $G$ dan $V_{\text {in }}$ dimana pin $G$ adalah kabel negatif dan $V_{\text {in }}$ adalah kabel positif, daya 4,55 Volt tersebut dialirkan ke tiga sensor DHT11, pada kabel hijau yang dihubung dari masing-masing sensor DHT11 ke pin D5, D6 dan D7 yang mampu mengirim data suhu pada DHT11 ke NodeMcu. Fungsi dari pin D5, D6 dan D7 dapat dilihat pada Tabel 3. Secara teknis DHT11 mampu menerima tegangan input sebesar 3,5 sampai dengan 5 VDC dengan sistem komunikasi sensor serial (Single - Wire Two Way) dangan kemampuan dapat monitoring suhu $0^{\circ} \mathrm{C}$ sampai dengan $50^{\circ} \mathrm{C}$ dengan akurasi suhu kurang lebih $2^{\circ} \mathrm{C}$. Untuk fungsi dari tiga kaki pin pada DHT11 yaitu pin VCC yang berfungsi menerima tetangan input $5 \mathrm{~V}$, pin GND berfungsi sebagai Ground dan pin DOUT berfungsi untuk Data output serial.

Tabel 3. Fungsi pin ESP8266

\begin{tabular}{|c|c|c|}
\hline $\mathrm{No}$ & Nama pin & Fungsi \\
\hline 1 & Pin D5 & $\begin{array}{l}\text { Berfungsi mengambil data } \\
\text { suhu pada DHT11 di rack } \\
\text { server } 1 \text { yang kemudian } \\
\text { dikirim ke platform } \\
\text { cayenne }\end{array}$ \\
\hline 2 & Pin D6 & $\begin{array}{l}\text { Berfungsi mengambil data } \\
\text { suhu pada DHT11 di rack } \\
\text { server } 2 \text { yang kemudian } \\
\text { dikirim ke platform } \\
\text { cayenne }\end{array}$ \\
\hline 3 & Pin D7 & $\begin{array}{l}\text { Berfungsi mengambil data } \\
\text { suhu pada DHT11 di rack } \\
\text { server } 3 \text { yang kemudian } \\
\text { dikirim ke platform } \\
\text { cayenne }\end{array}$ \\
\hline
\end{tabular}

Kemudian slot pada USB micro di NodeMcu dihubungkan dengan kabel data atau kabel charger ponsel cerdas dengan daya 5 Volt kemudian diturunkan menjadi 3 Volt dengan menggunakan AMS117 pada NodeMcu. Secara umum rancangan perangkat keras dapat dilihat pada Gambar 3. 


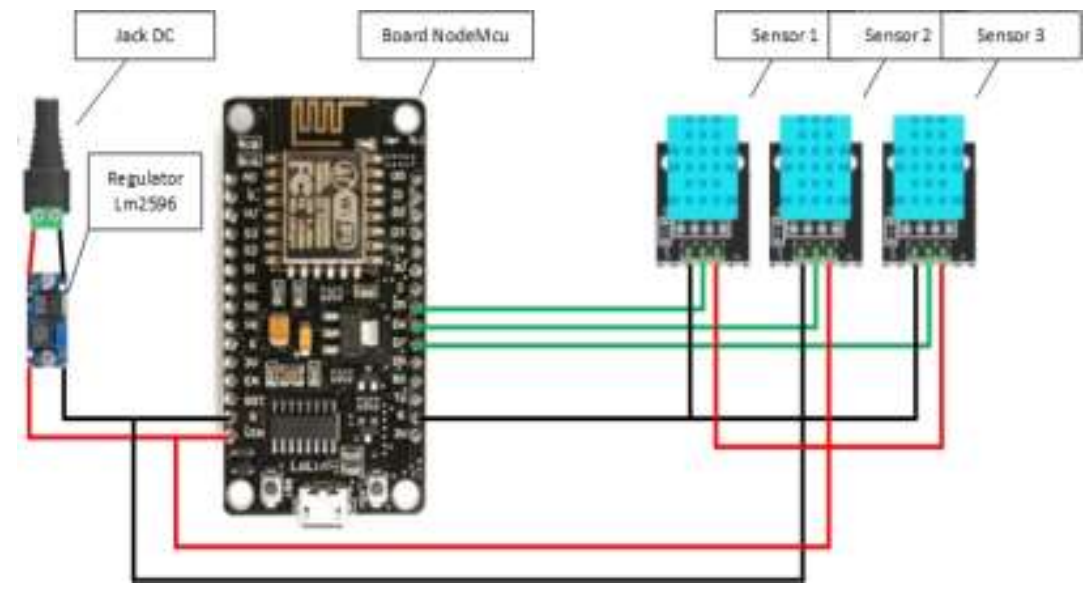

Gambar 3. Rancangan Perangkat Keras

Sistem Kerja pemantauan suhu diawali dengan menginisial ESP8266, apabila terjadi koneksi maka Arduino IDE menampilkan serial print: connecting to ssid, bila tidak maka kembali ke inisialisasi ESP8266. Kemudian DHT11 di inisialisasi maka data suhu akan terkirim ke Cayenne yang kemudian menampilkan informasi suhu. Gambar diagram alir dari program yang dirancang dapat dilihat pada Gambar 4.

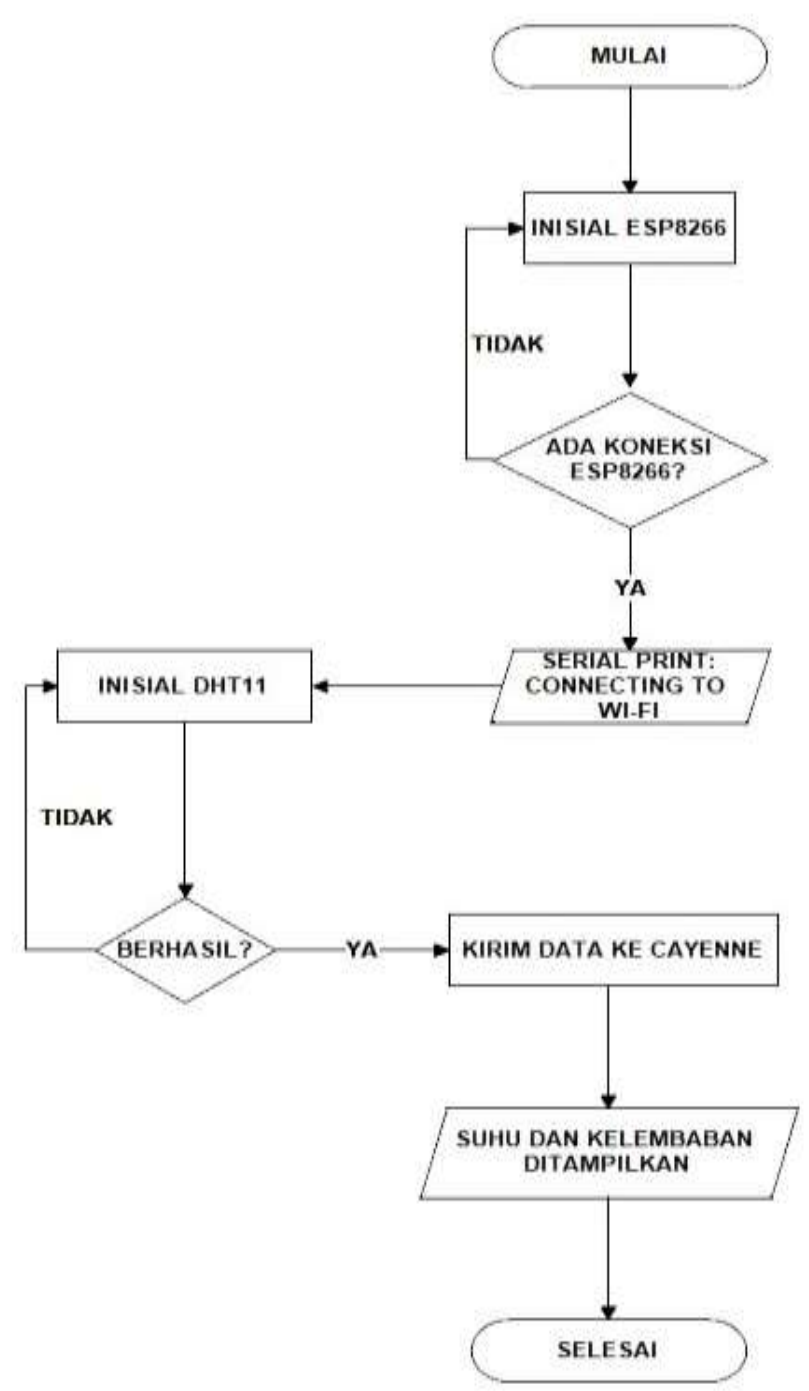

Gambar 4. Diagram Alir Perancangan Program 


\section{Implementasi}

Sebelum diimplementasikan, perlu dilakukan tahap instalasi aplikasi untuk mendukung kinerja dari perangkat yang dirancang. Aplikasi seperti Arduino IDE yang merupakan aplikasi open source sehingga dapat diunduh secara bebas di internet, fungsi dari aplikasi ini untuk membangun program yang mendukung infrastruktur yang telah dirancang. Setelah instalasi Arduino Ide maka selanjutnya adalah install library ESP8266, library DHT11 dan library Cayenne. Tahap selanjutnya adalah membuat akun di Cayenne. Setelah terdaftar maka tahap berikut yaitu melakukan koneksi akun Cayenne dengan board NodeMcu.

Dalam penelitian ini, tiga rack server diletakkan sensor DHT11, untuk NodeMcu diletakkan di tengah rack server. Masing-masing sensor diletakkan di rack server bertujuan untuk memperoleh informasi suhu pada rack dengan cepat karena berada diantara mesin-mesin server yang beroperasi. Pengujian dan pengambilan data pada penelitian ini diambil satu hari pada jam kerja mulai dari jam 08:45 WIT sampai dengan 10:45 WIT dengan interval waktu 5 menit. Karena NodeMcu mendukung standar Wi-Fi IEEE $802.11 \mathrm{~b} / \mathrm{g} / \mathrm{n}$, maka pengaturan alamat IP diambil dan terhubung dengan Wi-Fi UNIPA. Pada rack 1 perangkat yang beroperasi seperti tiga unit komputer server, dua monitor komputer dan satu unit UPS. Untuk rack 2 perangkat yang beroperasi antara lain satu switch, satu unit monitor, dua komputer server, satu unit UPS. Pada rack 3 terdapat tujuh unit Acces Point router LTE, dua unit switch, satu unit router, satu unit Mikrobits Ainos, satu unit switch, satu unit switch juniper, satu unit switch allied telesis fiber optic.

\section{Validasi Sistem}

Untuk memastikan bahwa alat sensor sistem yang dirancang sudah benar, maka setelah sensor DHT11 dipasang pada tiga rack server dan board NodeMcu diletakkan di tengah rack server seperti pada Gambar 5.

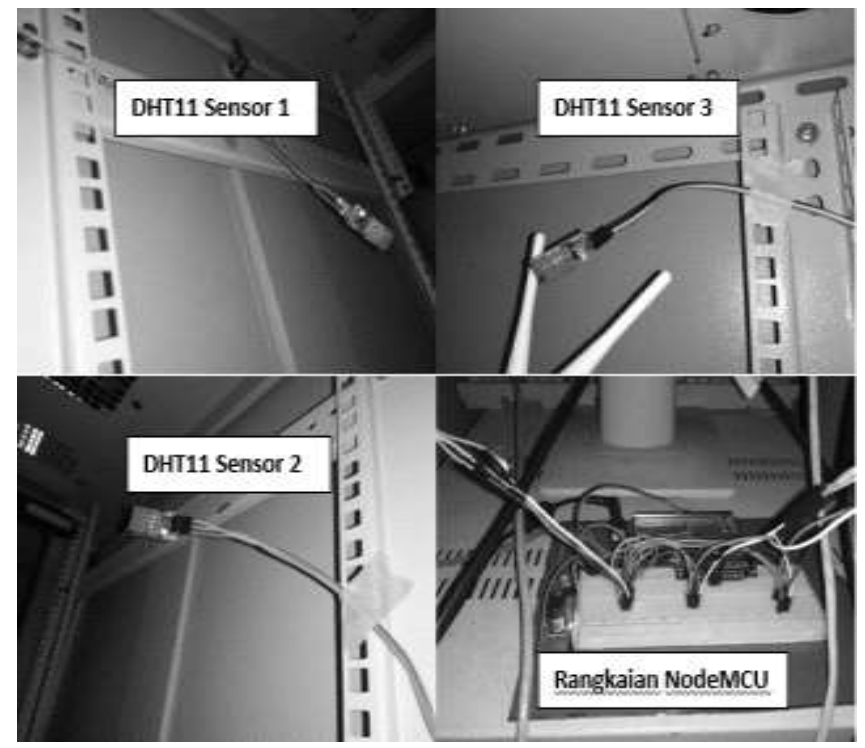

Gambar 5. Posisi Sensor

Setelah alat terpasang dengan benar maka saat koneksi dengan platform Canyenne ketiga sensor DHT11 kemudian menampilkan data suhu dan kelembapan. Apabila sudah benar maka tampilan Cayenne seperti pada Gambar 6 yang menunjukkan suhu terbaca oleh sensor yang terkirim ke sistem. 


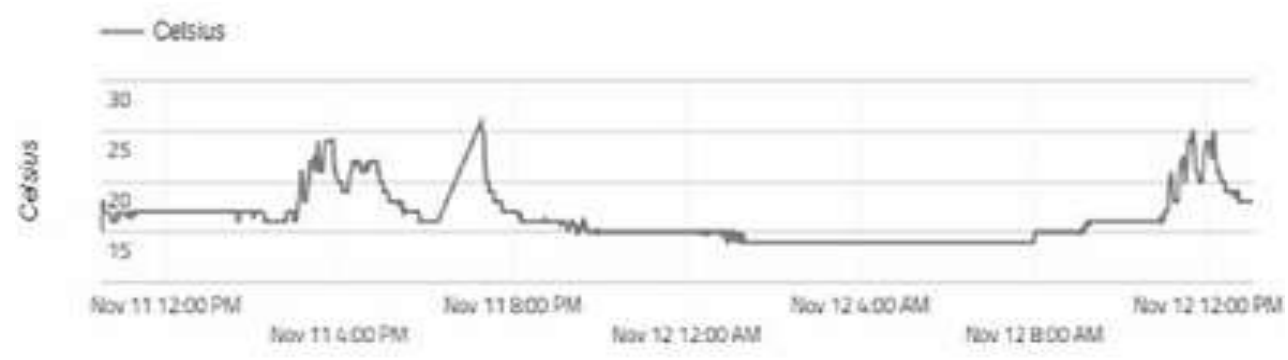

Gambar 6. Grafik Suhu Terbaca oleh Sensor

Gambar 7 menampilkan data suhu dan kelembapan yang dibaca oleh sensor dan ditampilkan oleh Cayenne. Ponsel cerdas juga dapat dipakai untuk memantau suhu dan kelembapan yang terbaca oleh sensor, dimana aplikasi Cayenne dapat dengan mudah di unduh di play store dan dioperasikan.

\section{HASIL DAN PEMBAHASAN}

Data suhu dan kelembapan dapat dibaca oleh sensor DHT11, kemudian dapat ditampilkan pada layar monitor maupun perangkat seluler. Jika tidak ada koneksi internet maka data suhu tidak dapat dilihat pada aplikasi Cayenne pada Gambar 7.

Data suhu yang terbaca oleh DHT11 tersimpan dalam media penyimpan pada perangkat keras yang dipakai dalam penelitian ini. Informasi dapat ditampilkan dalam bentuk grafik waktu pengambilan data suhu. Data suhu yang tersimpan dapat diambil dan diolah pada aplikasi pengolah angka seperti MS.Excel.

Pada penelitian ini aplikasi Cayenne yang dapat beroperasi di android, merupakan perangkat lunak yang gratis. Fungsi Cayenne di dalam penelitian ini agar mempermudah operator dalam memantau dan memdapatkan data suhu pada periode waktu tertentu. Pengujian dalam penelitian ini dengan membandingkan peralatan yang dirancang dengan thermometer HT-2. Dimana sensor DHT11 dan thermometer HT-2 dipasang pada rack server 1, 2 dan 3 seperti pada Gambar 8.

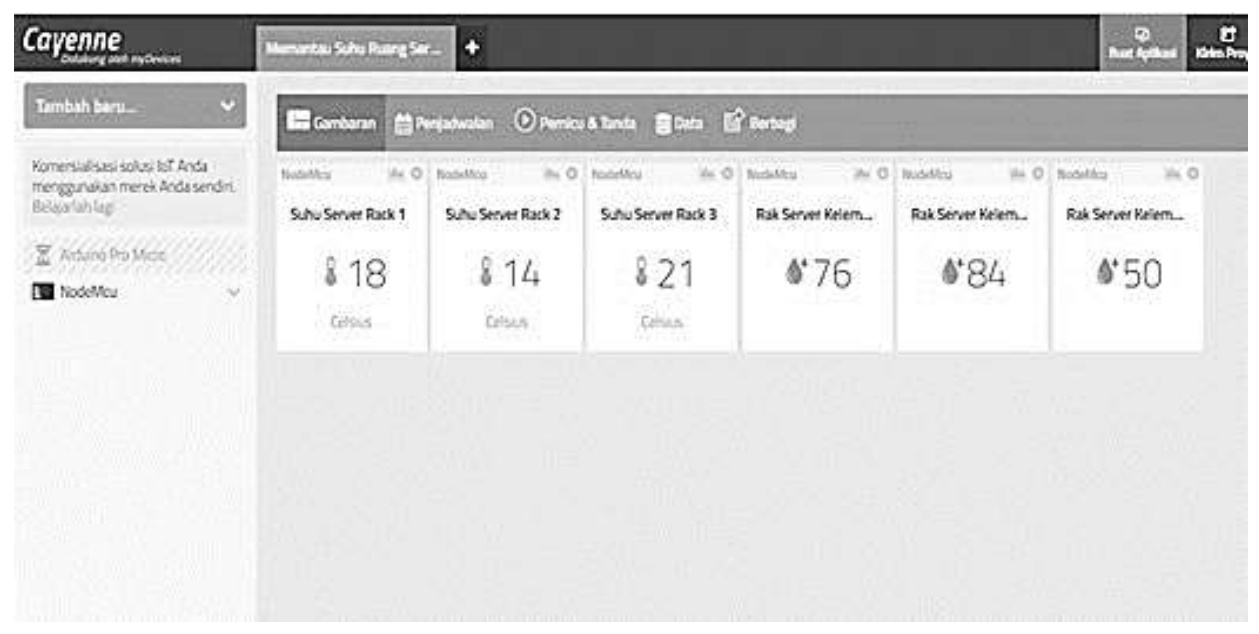

Gambar 7. Contoh Tampilan Layar Cayene 


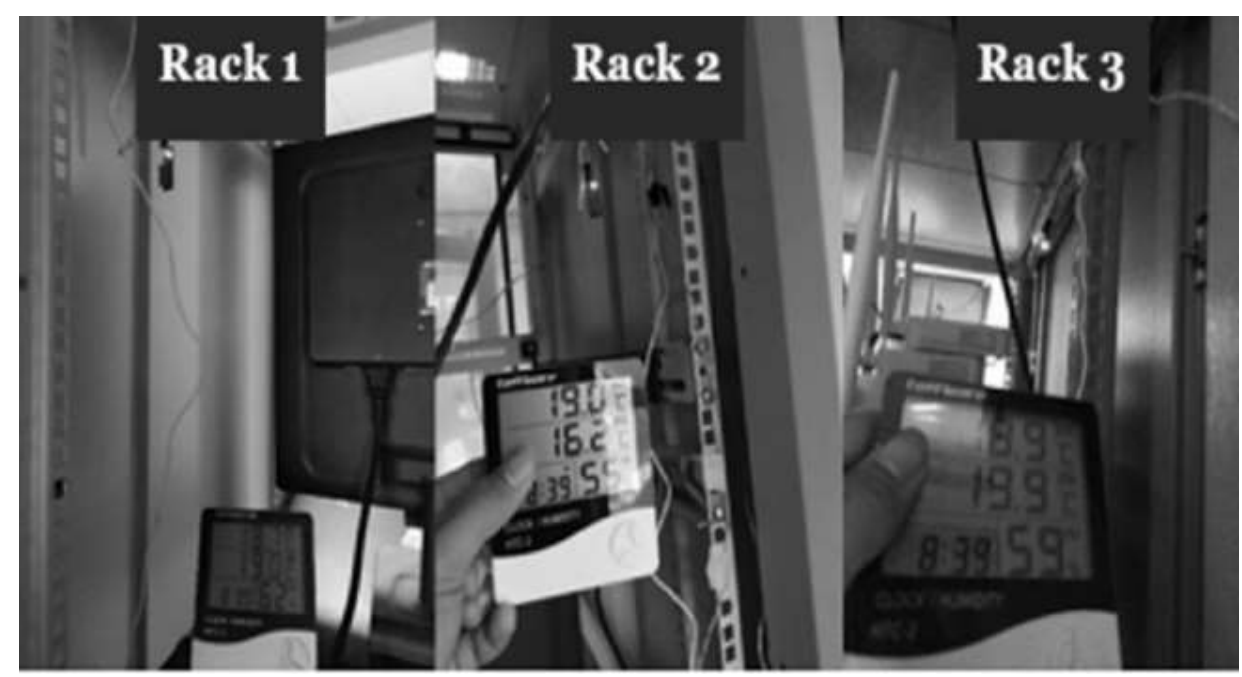

Gambar 8. Proses Pengujian Alat

Data hasil uji kemudian di hitung dengan mencari nilai selisih antara thermometer dengan DHT11 seperti pada Persamaan (1).

$$
R=x_{\max }-x_{\min }
$$

Dimana $x_{\max }$ adalah nilai terbesar dan $x_{\min }$ adalah nilai terkecil. Setelah memperoleh nilai error atau selisih nilai data, selanjutnya ke tahap mencari nilai rata-rata persen error seperti pada Persamaan (2).

$$
\bar{x}=\frac{R}{R_{1}} \times 100 \%
$$

Dimana $\bar{x}$ adalah nilai rata-rata, $\mathrm{R}$ adalah nilai selisi dan $\mathrm{R}_{1}$ adalah nilai dari thermometer. Berdasarkan hasil pengamatan perbandingan data dari sensor DHT11 dengan thermometer HT-2 pada masing-masing rack maka hasil kalkulasi yang diperoleh nilai rata-rata sebesar 1,5\% untuk rack 1, 2,6\% untuk rack 2 dan untuk rack 3 sebesar $3 \%$.

Selanjutnya data yang diperoleh dari sensor DHT11 pada rack 1, 2 dan 3 dibandingkan hasil pengolahan datanya yang dapat dimunculkan dalam bentuk grafik seperti pada Gambar 9 .

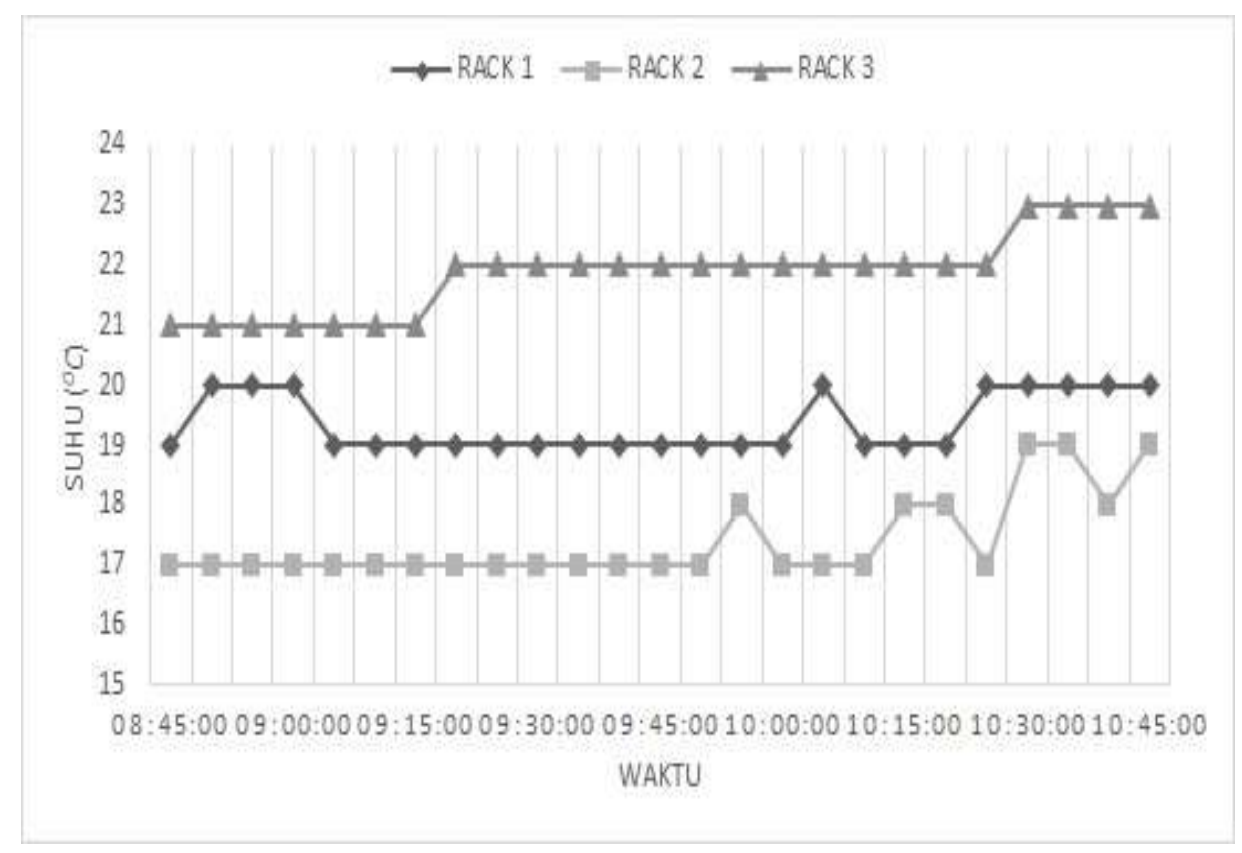

Gambar 9. Grafik Perbandingan Data Suhu 
Dari Gambar 9 dapat diketahui bahwa suhu rack 3 lebih tinggi dibandingkan dengan rack 1 dan 2 , karena rata-rata suhu pad rack 3 sebesar $21,8^{\circ} \mathrm{C}$, sedang untuk rack 1 nilai rata-rata suhu sebesar $19,3^{\circ} \mathrm{C}$ dan untuk rack 2 nilai rata-rata suhu sebesar $17,4^{\circ} \mathrm{C}$. Hal ini terjadi karena faktor mesin yang aktif pada masing-masing rack, semakin banyak mesin yang aktif maka kondisi suhu didalam rack semakin tinggi seperti pada rack 3 .

Dalam penelitian ini perancangan sampai hasil eksperimen menggunakan pola SDLC, dimana tahapan penelitiannya di bagi menjadi empat tahap berbeda dengan pola penelitian yang pernah ada dan penelitian ini lebih fokus pada pengukuran suhu di rack server (Hakiki, Darusalam, \& Nathasia, 2020), hasil pada rack 2 menunjukkan suhu dibawah standar yang telah ditentukan pada standar TIA (Gunawan \& Oktiawati, 2020). Peralatan yang di rancang sederhana tetapi dapat di pakai untuk mengukur suhu pada rack server dan periode waktu pemantauan lebih panjang (Adhiwibowo, Daru, \& Hirzan, 2020). Penelitian ini memberi informasi suhu secara waktu nyata menggunakan Canyenne dan belum memanfaatkan aplikasi layanan pesan instan sebagai media pemberitahuan secara waktu nyata.

\section{KESIMPULAN DAN SARAN}

Dalam penelitian ini, dibangun sebuah purwarupa yang berfungsi melakukan pemantauan kondisi suhu pada rack server. Dari hasil eksperimen menunjukkan kalau purwarupa yang dirancang bisa memberikan informasi setiap perubahan suhu rack yang dipantau.

Masing-masing rack server memiliki standar suhu yang baik bila disesuaikan dengan standar TIA, kecuali pada rack 2 yang bila nilai suhunya dirata-ratakan maka diperoleh suhunya sebesar $17,4^{\circ} \mathrm{C}$. Suhu pada masing-masing rack server dipengaruhi oleh banyaknya mesin yang beroperasi, sehingga diperlukan penataan mesin secara merata pada rack server agar suhu dapat merata di masing-masing rack server, karena penelitian ini membuktikan bahwa suhu berbeda secara jelas dilokasi masing-masing rack server.

Untuk pengembangan selanjutnya dapat menambahkan mekanisme seperti sensor tambahan untuk aliran udara, sensor tekanan yang dikombinasikan dengan sensor yang dirancang demi memperluas ruang lingkup penelitian.

\section{DAFTAR PUSTAKA}

Adhiwibowo, W., Daru, A. F., \& Hirzan, A. M. (2020). Temperature and Humidity Monitoring Using DHT22 Sensor and Cayenne API. Jurnal Transformatika, 17(2), 228-233.

Bajrami, X., \& Murturi, I. (2018). An efficient approach to monitoring environmental conditions using a wireless sensor network and NodeMCU. E \& i Elektrotechnik und Informationstechnik, 135(3), 294-301.

Bhawiyuga, A., \& Yahya, W. (2019). Sistem Monitoring Kualitas Air Kolam Budidaya Menggunakan Jaringan Sensor Nirkabel Berbasis Protokol LoRa. Jurnal Teknologi Informasi dan Ilmu Komputer, 6(1), 99-106.

Boonchieng, E., Chieochan, O., \& Saokaew, A. (2018). Smart Farm: Applying the Use of NodeMCU, IOT, NETPIE and LINE API for a Lingzhi Mushroom Farm in Thailand. IEICE TRANSACTIONS on Communications, E101-B(1), 16-23.

Gunawan, B. I., \& Oktiawati, U. Y. (2020). Server Room Temperature and Monitoring System Using Fuzzy Based on RobotDyn Microcontroller. Jurnal RESTI (Rekayasa Sistem dan Teknologi Informasi), 4(1), 1-9. 
Hakiki, M. I., Darusalam, U., \& Nathasia, N. D. (2020). Konfigurasi Arduino IDE Untuk Monitoring Pendeteksi Suhu dan Kelembapan Pada Ruang Data Center Menggunakan Sensor DHT11. Jurnal Media Informatika Budidarma, 4(1), 150-156.

Kurniawan, D. E., Iqbal, M., Friadi, J., Borman, R. I., \& Rinaldi, R. (2019). Smart Monitoring Temperature and Humidity of the Room Server Using Raspberry Pi and Whatsapp Notifications. Journal of Physics: Conference Series, 1351, 012006. IOP Publishing.

Lestariningsih, T., Artono, B., Hidayatullah, N., \& Kusbandono, H. (2019). Microcontroller and Android HMI Based Water Level and Control System. EAI Endorsed Transactions on Internet of Things, 5(17). Retrieved June 20, 2020, from https://eudl.eu/doi/10.4108/eai.28-1-2019.162807

Mahmud, M. S. A., Buyamin, S., Mokji, M. M., \& Abidin, M. S. Z. (2018). Internet of Things based Smart Environmental Monitoring for Mushroom Cultivation. Indonesian Journal of Electrical Engineering and Computer Science, 10(3), 847-852.

Ouldzira, H., Mouhsen, A., Lagraini, H., Chhiba, M., Tabyaoui, A., \& Amrane, S. (2019). Remote monitoring of an object using a wireless sensor network based on NODEMCU ESP8266. Indonesian Journal of Electrical Engineering and Computer Science, 16(3), 1154-1162.

Prasetyo, B. E., Putra, W. H. N., Syauqy, D., Bhawiyuga, A., Wibowo, S. S., Ronilaya, F., Siradjuddin, I., et al. (2020). Sistem Monitoring Trafo Distribusi PT.PLN (Persero) berbasi IoT. Jurnal Teknologi Informasi dan Ilmu Komputer, 7(1), 205-210.

Rahman, R. A., Hashim, U. R., \& Ahmad, S. (2020). IoT based temperature and humidity monitoring framework. Bulletin of Electrical Engineering and Informatics, 9(1), 229-237-237.

Rantelinggi, P. H., Paiki, F. F., \& Rantelobo, K. (2017). Performance of routing protocol in MANET with combined scalable video coding. 2017 4th International Conference on Electrical Engineering, Computer Science and Informatics (EECSI) (pp. 1-4). Presented at the 2017 4th International Conference on Electrical Engineering, Computer Science and Informatics (EECSI).

Rantelinggi, Parma Hadi, \& Djanali, S. (2015). Kinerja Protokol Routing Pada Lingkungan Wireless Mesh Network Dengan Combined Scalable Video Coding. JUTI: Jurnal Ilmiah Teknologi Informasi, 13(1), 86-94-94.

Rohadi, E., Adhitama, D. W., Ekojono, E., Ariyanto, R., Asmara, R. A., Ronilaya, F., Siradjuddin, I., et al. (2018). Sistem Monitoring Budidaya Ikan Lele Berbasis Internet Of Things Menggunakan Raspberry Pi. Jurnal Teknologi Informasi dan Ilmu Komputer, 5(6), 745-750.

Sabiq, A., \& Budisejati, P. N. (2017). Sistem Pemantauan Kadar pH, Suhu dan Warna pada Air Sungai Melalui Web Berbasis Wireless Sensor Network. Jurnal Teknologi dan Sistem Komputer, 5(3), 94100.

Sethi, P., \& Sarangi, S. R. (2017, January 26). Internet of Things: Architectures, Protocols, and Applications. Journal of Electrical and Computer Engineering. Review Article, Hindawi. Retrieved June 20, 2020, from https://www.hindawi.com/journals/jece/2017/9324035/ 